\title{
An Ultra-High Speed Image Dissecting Camera for Photographing Strong Shock Waves
}

\author{
Kenneth B. Earnshaw and Charles M. Benedict
}

(May 18, 1962)

\begin{abstract}
An ultra-high speed image dissecting camera patterned after an original design by Sultanoff has produced motion pictures of shock waves having velocities greater than $7 \mathrm{~cm} /$ microsecond. The camera is readily adaptable to either streak or framing photography. A discussion of the camera system design indicates the modifications of the original design which allow for greater flexibility of camera use. Several photographs of high speed shock waves are used to demonstrate the various modes of camera operation. The very high framing rate $\left(1 \times 10^{3} /\right.$ second) and the easy adaptation from streak to framing photography make this camera a particularly useful tool for research in the field of very fast shock waves.
\end{abstract}

\section{Introduction}

The design of a $10^{8}$ frame/sec image dissecting camera by Morton Sultanoff $[1],{ }^{1}$ published in 1950 , provided a means for observing extremely fast events. Although the Sultanoff design is invariably mentioned in comprehensive surveys of high-speed photography $[2,3,4]$, very little information is available from the literature concerning the use of this type of camera in high-speed shock wave research. It is the purpose of this paper to report the results obtained from a Sultanoff type camera system developed in this laboratory. The discussion will include camera and film viewer design, and the techniques used in obtaining photographs.

\section{Camera Design}

Since the Sultanoff camera obtains very high framing rates by using the principles of image dissection, perhaps a brief discussion of image dissection is in order.

Image dissection photography, as applied in the Sultanoff camera, consists of optically dissecting or sampling individual pictures at regular intervals so that each picture is composed of a large number of lines uniformly spaced over the picture area (as in a television picture). If picture sampling line widths are narrow compared to the distance between lines, many pictures may be recorded on one photographic plate by registering each picture grid pattern at a slightly different space to give an interlacing of all the pictures over a common area. Individual pictures may be seen by viewing the composite photograph through a grid composed of transparent lines ruled on an optically opaque plate, as in figure 1 . The grid line widths and line spacings must of course be identical to the corresponding lines and spaces of the dissected photographs. By registering the grid at different positions across a composite photograph, each picture can be seen in turn.

1 Figures in brackets indicate the literature references on page 310.
As an example, if each picture is dissected into lines $13 \mu$ wide, with $390 \mu$ between lines, as many as 31 pictures can be displayed on a common area. Figure 2 is a composite picture of 10 photographs dissected as outlined above. The 10 photographs are displayed separately in figure 3. Each photograph is obtained by indexing the grid, shown in figure 1, at the proper position on the composite.

This example shows only that many individual pictures may be interwoven on a single photographic plate and that the individual photographs can be taken from the composite photograph. In applying the principles of image dissection to high-speed framing photography, some space resolution is deliberately sacrificed in order to achieve time resolution between the photographs which are interwoven on a single photographic plate. In practice, the necessary time resolution is achieved by using a rotating mirror to sweep a dissected, time-varying image across a photographic plate to obtain the interlacing of many images as a function of time.

Since the basic design principles of the grid framing camera are covered thoroughly elsewhere $[1,2]$, only the general design features and the improvements incorporated in the camera construction are discussed here. Rather complete details of the commercial components used are presented in appendix I. Suffice it to say that the image is dissected by a grid, as in figure 1, placed at the focal plane of an objective lens and that the dissected image is reimaged on film after reflection from a rotating mirror. The rotating mirror provides a time dependent indexing of successive pictures on the film.

A pictorial view of the optical system for the ultrahigh speed camera is shown in figure 4. Although the system is patterned after the original Sultanoff design, the camera uses a Sinar commercial view camera for holding and focusing the first lens. This permits rapid focusing and lens changing as well as serving essentially as an optical bench on which mirrors, filters, shutters, etc., can be mounted easily if desired. A trap door above and immediately behind the multislit focal plane shutter (fig. 4) provides for convenient focusing. The door, when opened, auto- 


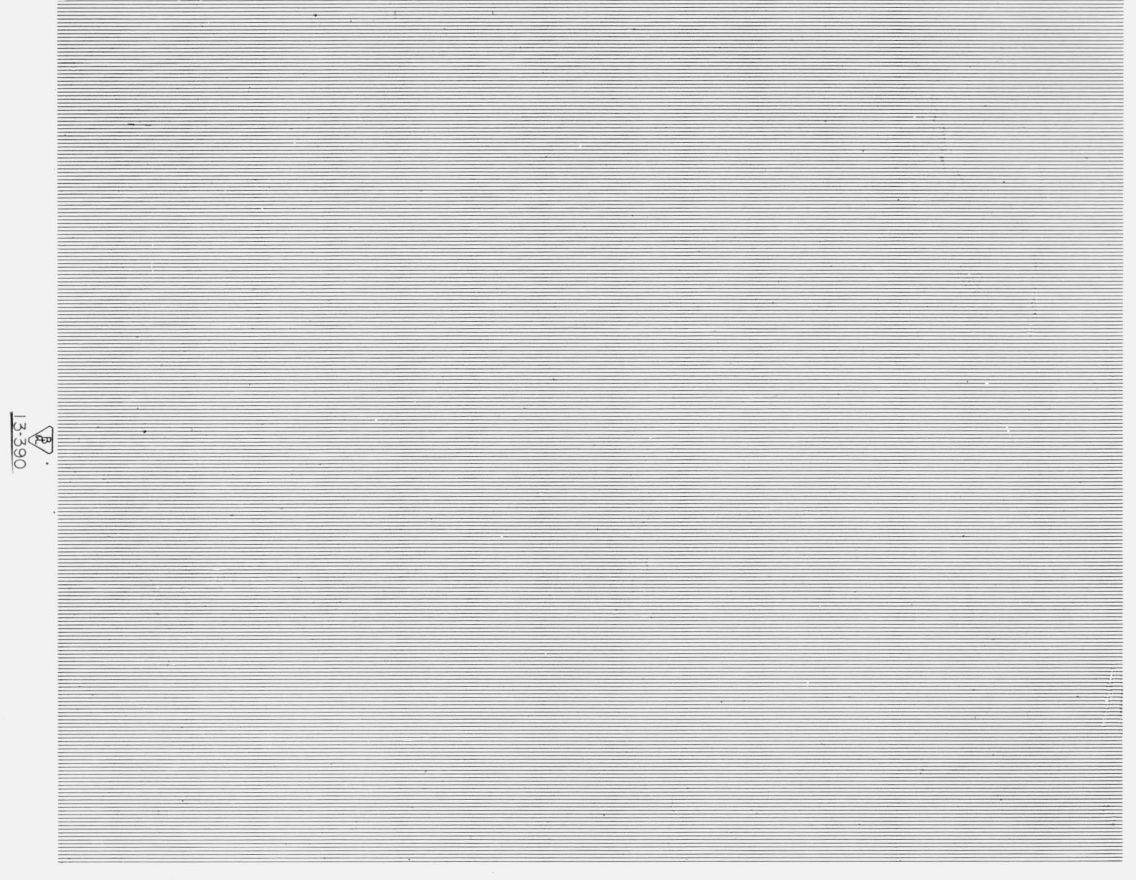

Figure 1. Contact print of an image dissecting grid. Slit width is $13 \mu$ and the distance between slit centers is $403 \mu$.

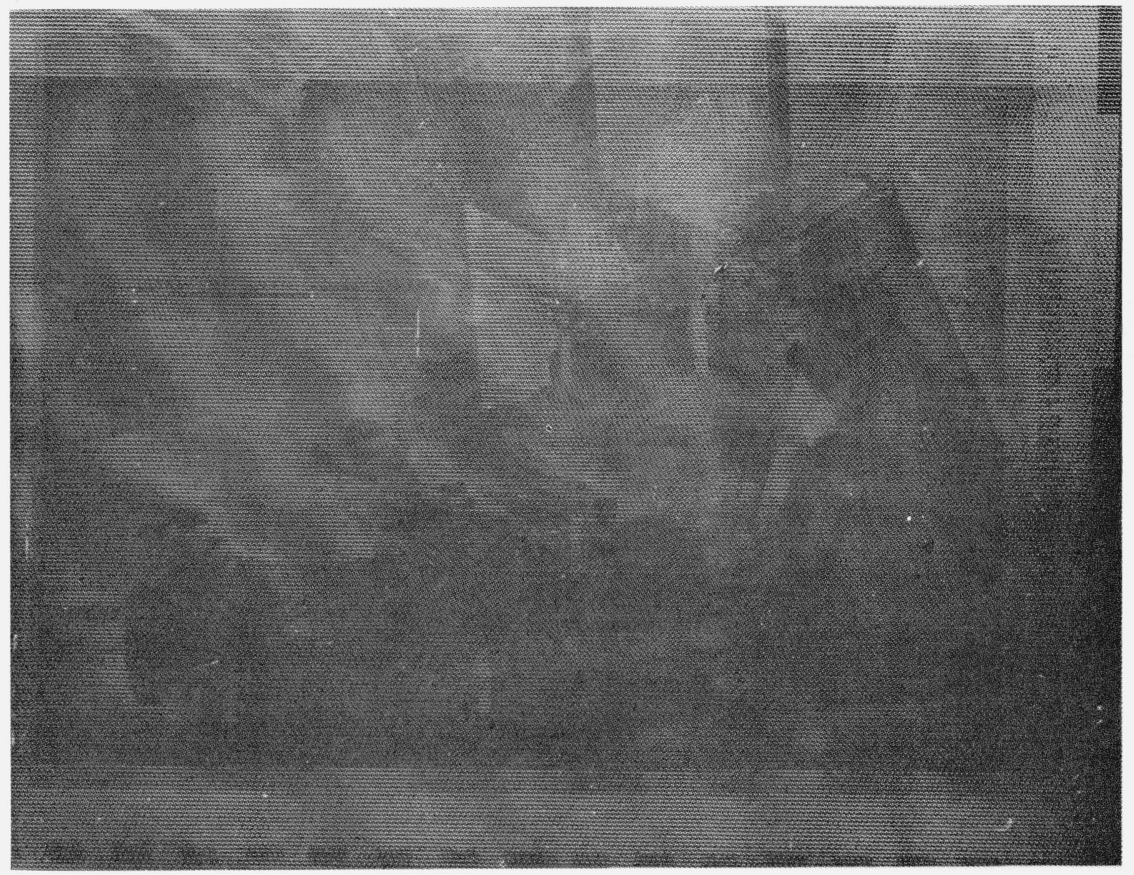

FIGURE 2. Enlarged print of a composite negative containing 10 dissected pictures.

matically swings down a focusing mirror at a $45^{\circ}$ angle to the focal plane, so that the image may be viewed from above. In addition, the camera incorporates a removable grid holder so that grids can be interchanged in a matter of a few seconds. The grid holder provides for a Fresnel focal plane lens to be positioned just ahead of the grid so that light from lens 1 will be redirected to lens 2 (visible in fig. 4). The readily changeable grid holder permits rapid changeover to streak photography or to other grids which are designed for different shutter speeds. 

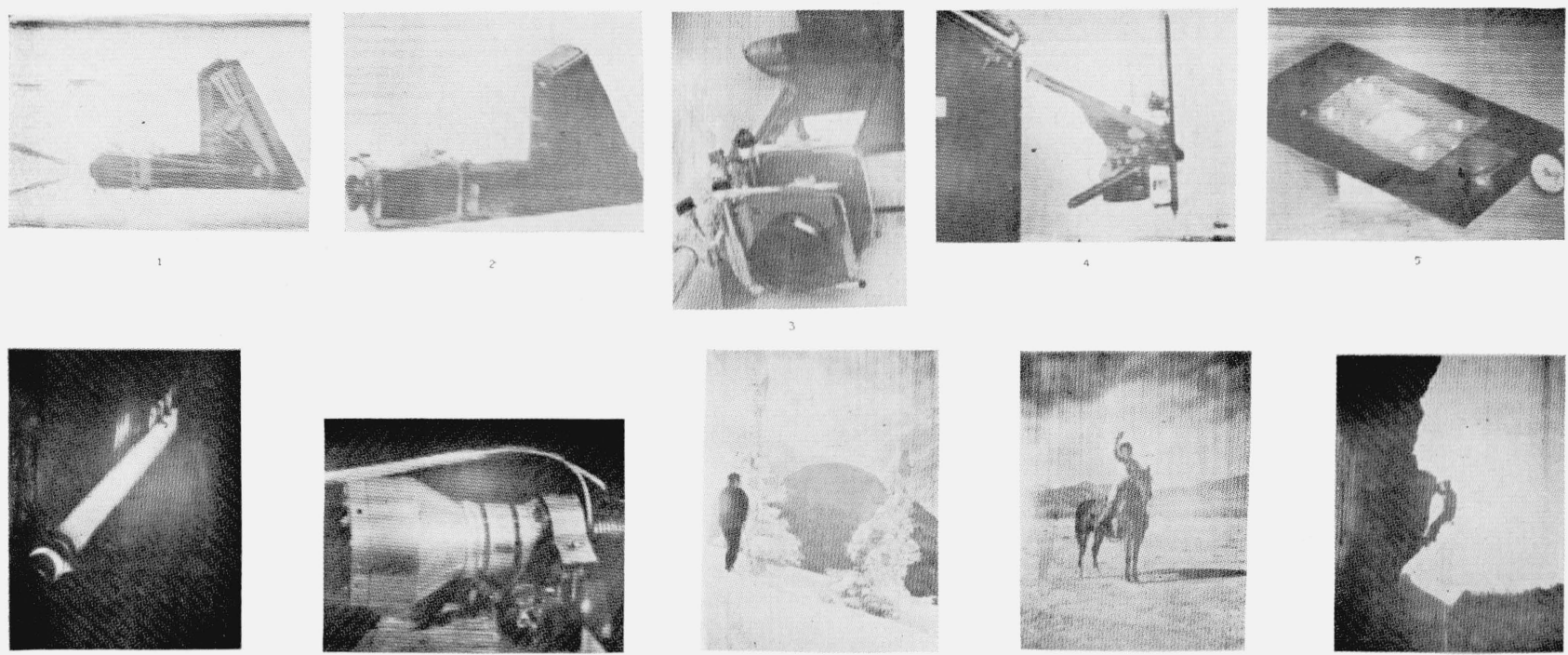

FIGURE 3. Ten individual photographs taken from the composite in figure 2 by indexing a grid at 10 positions on the composite negative.

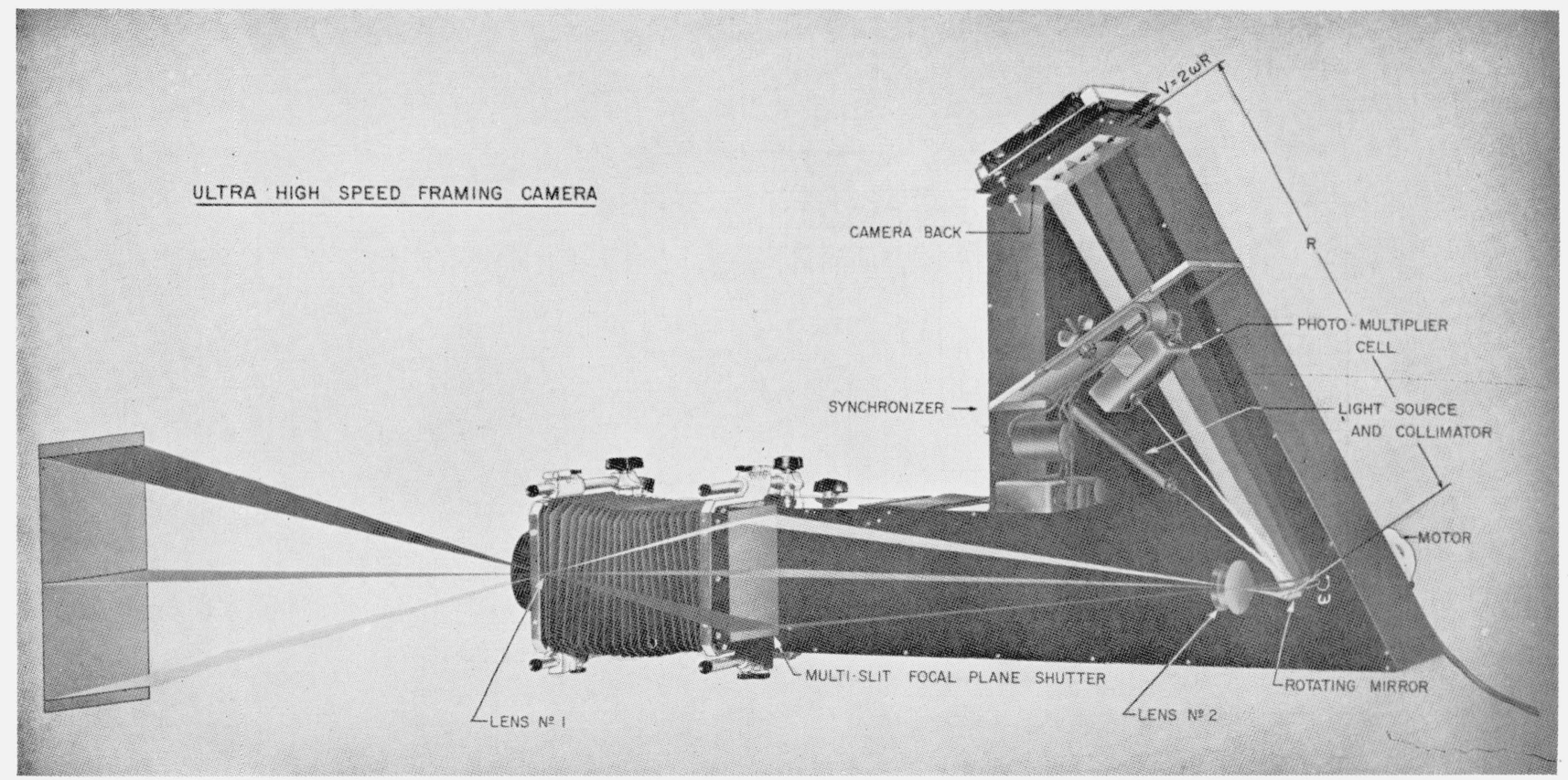

Figure 4. A pictorial view of the ultra-high speed camera.

The mirror surface is $2 \mathrm{in} . \times 2 \mathrm{in}$. and is rotated about an axis lying on the mirror surface. An electric hand grinder motor rotates the mirror at a maximum speed of 600 rps. A photograph of the camera is shown in figure 5 .

\section{Synchronization}

Since this type of camera is not continuous writing, it is necessary to have a precise method of synchronizing the event to the framing interval of the camera (the time at which the image is reflected onto the photographic plate). Synchronization is accomplished by reflecting a collimated beam of light from the rotating mirror (as shown in fig. 4). When the mirror is in proper position, the light beam enters the photomultiplier. The photomultiplier signal triggers a pulse generator which provides a $50-\mathrm{v}$ pulse for triggering the shock generating apparatus. The synchronizing circuit is wired so that pulses cannot leave the camera until a button switch on the camera is pushed. Synchronizing in this fashion 


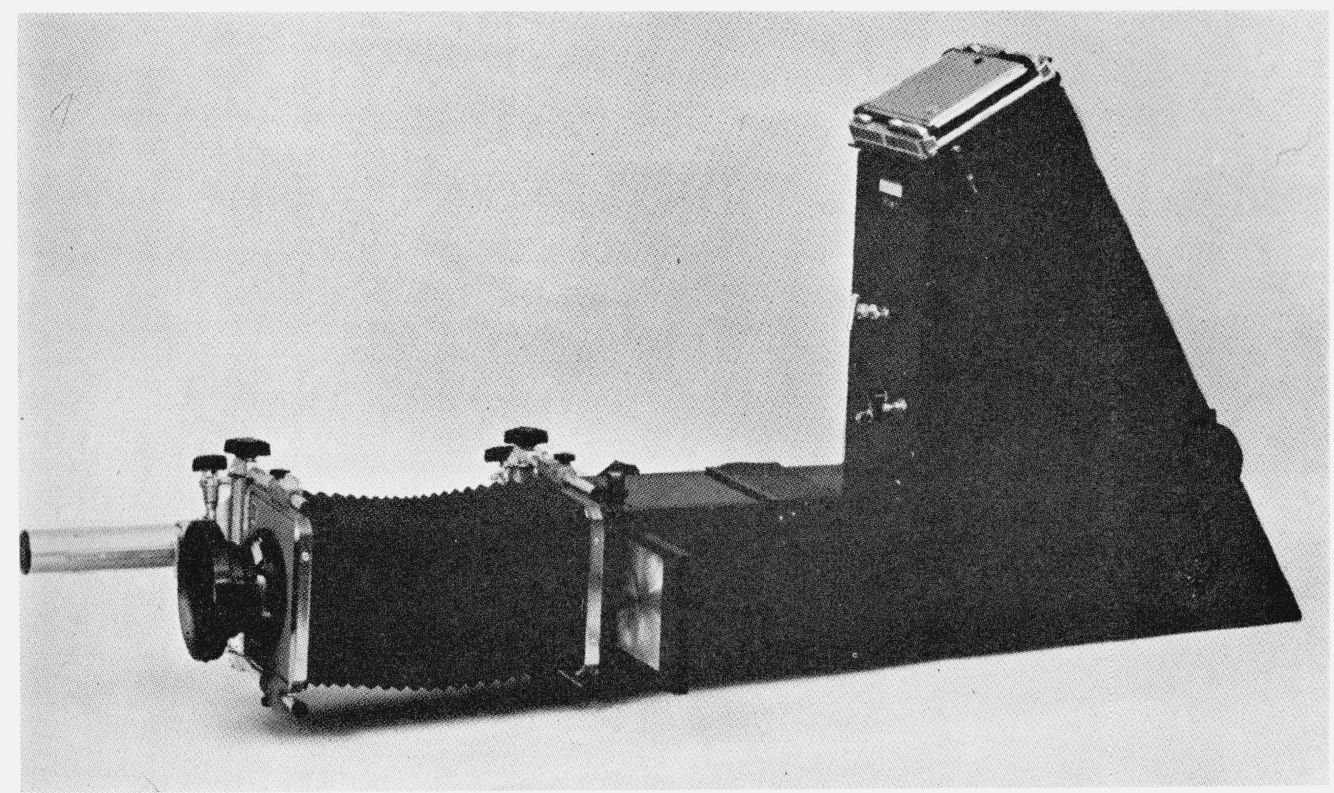

Figure 5. A side view of the camera with the grid holder partially removed.

PHOTOMULTIPLIER-SYNCHRONIZER CIRCUIT

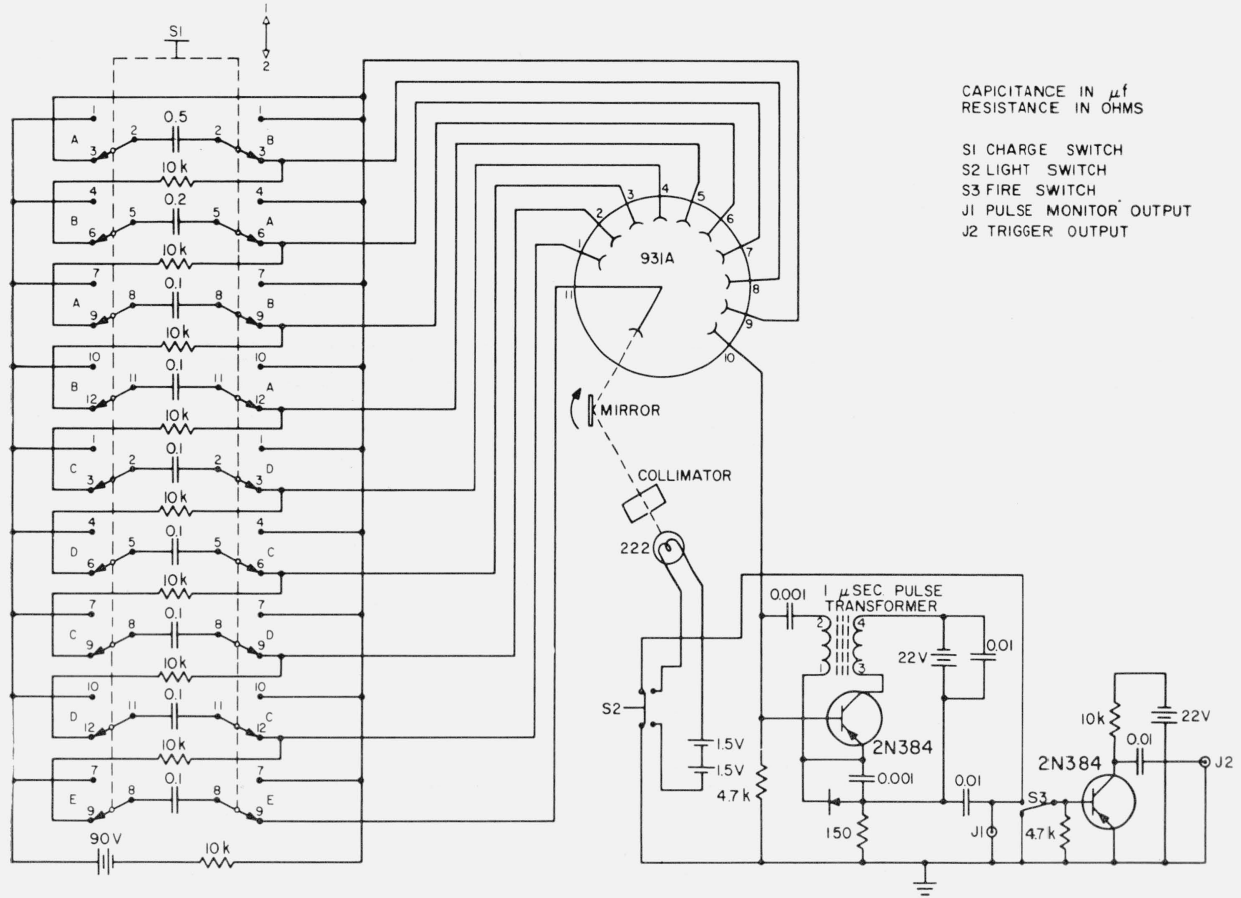

Figure 6. Schematic diagram of the photomultiplier synchronizer.

takes advantage of an effective optical leverage so that synchronization can be quite precise at any mirror rotation speed. Figure 6 is a schematic diagram of the synchronizer circuit. Note that a simple battery-condenser power supply is used. The photomultiplier is turned on by switching $\mathrm{S}-1$ from position 2 to position 1 and back to position 2 .
This charges a group of condensors in parallel and then discharges them in series across the photomultiplier elements. One switching operation will activate the photomultiplier for $8 \mathrm{~min}$. A photograph of the synchronizer assembly (removed from the front of the camera) is shown in figure 7. 


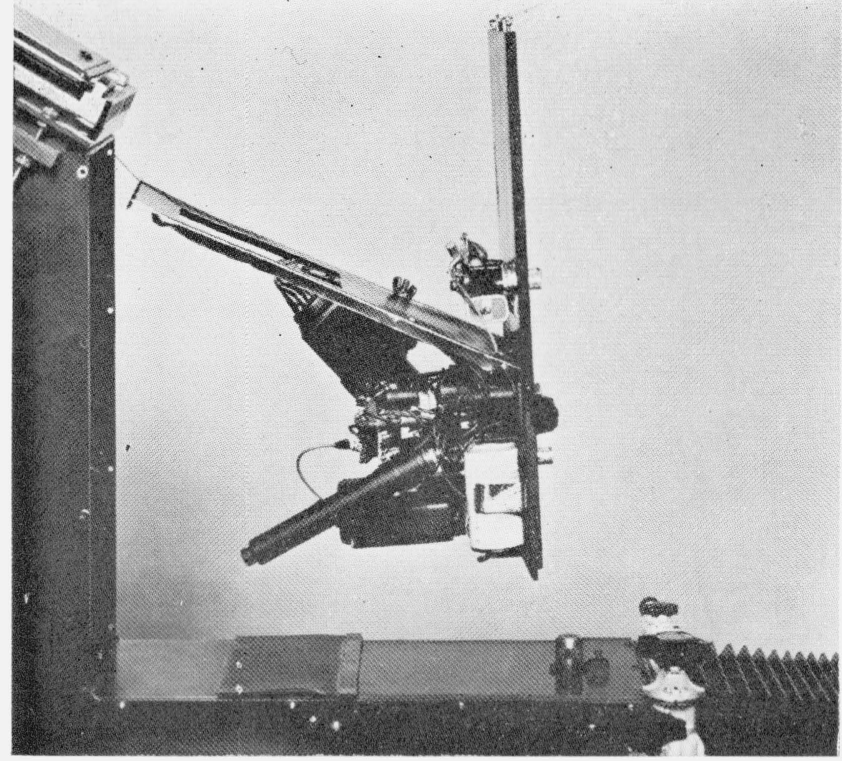

Figure 7. Photomultiplier synchronizer (removed from front of camera).

\section{Film Viewer}

The film viewer for unscrambling the composite photographs produced by the camera is shown in figure 8. Correct alinement of the photograph on the grid is accomplished by the alinement adjustment which rotates the disk shaped film holder. The disk is anchored in the top carriage which is moved over the base plated by a cam. The top carriage is spring loaded against the cam and is held to the base plate with dovetail slides. The orid is held in a countersunk hole in the base plate. Indexing of the photograph across the grid is accomplished by turning the indcxing adjustment. The worm gear drive (located under the cam) and the cam taper are such that one revolution of the knob produces a carriage movement of $0.001 \mathrm{in}$. Carriage position is easily read on the dial indicator. Photographs are normally viewed by placing the viewer over a light source. However, the entire film viewer is mounted on a board which can be placed in an enlarger for copy work.

For moving picture photography, the film viewer is motor driven as shown in figure 9. The variable transformer motor control and the three speed pulley drive provide for a range of viewing speeds of about $60: 1$. This range has been satisfactory for all photographs viewed so far. Moving picture records are obtained by positioning a movie camera above the viewer with a light source placed under the viewer. Figure 10 shows a typical arrangement for moving picture recording.

\section{Shock Wave Photography}

In any photographic observation of shock wave phenomenon, it is useful first to obtain streak photographs of the phenomena of interest. From the streak photographs, measurements of luminosity times permit one to calculate the optimum mirror speed for framing photography.

Streak photographs are obtained by replacing the grid with an opaque plate having a single transparent slit. For the work presented here, a rather coarse grid was used having all but the center slit masked off. Good alinement was easily accomplished by imaging the shock tube on the center line of the

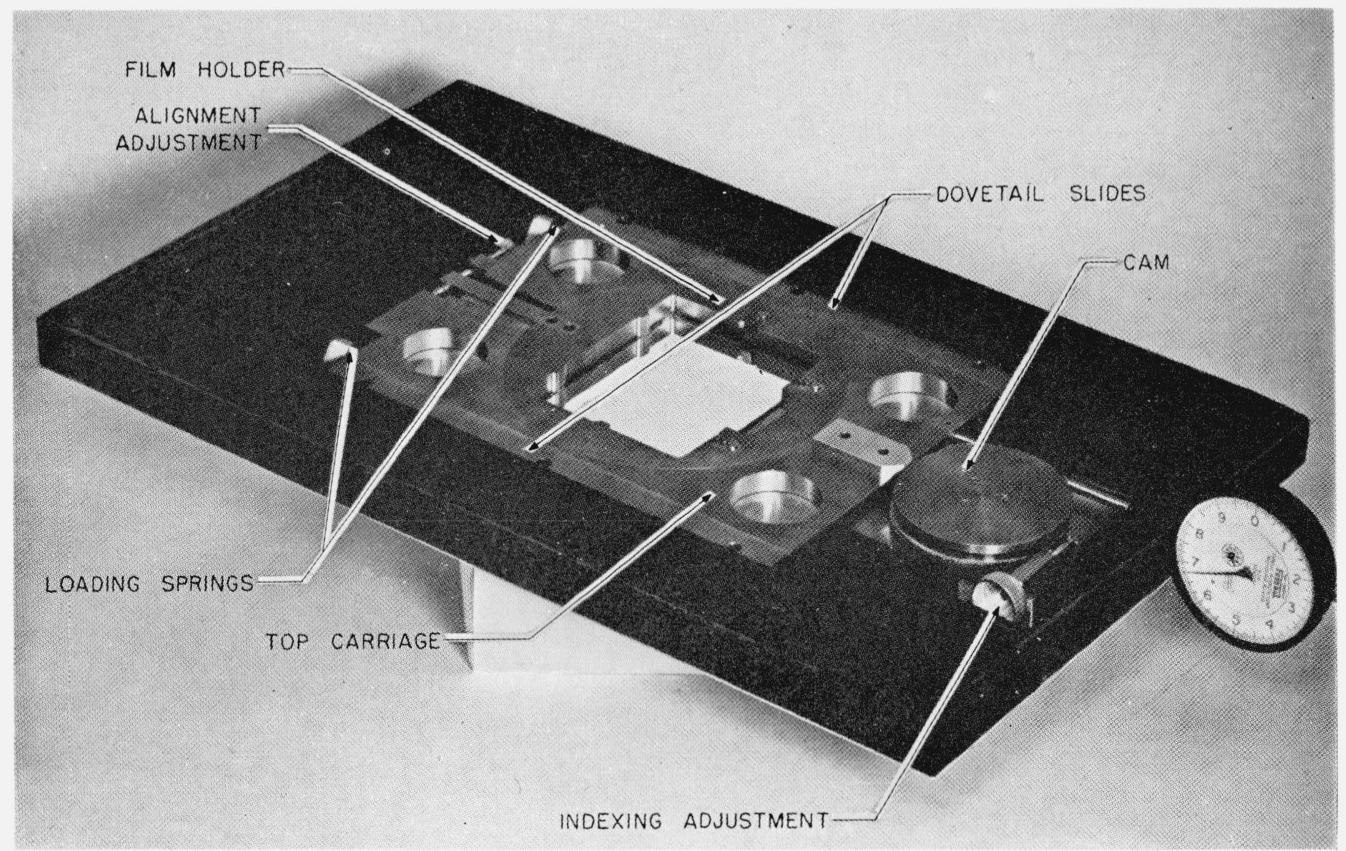

FiguRE 8. Film viewer for observing high speed photographs. 


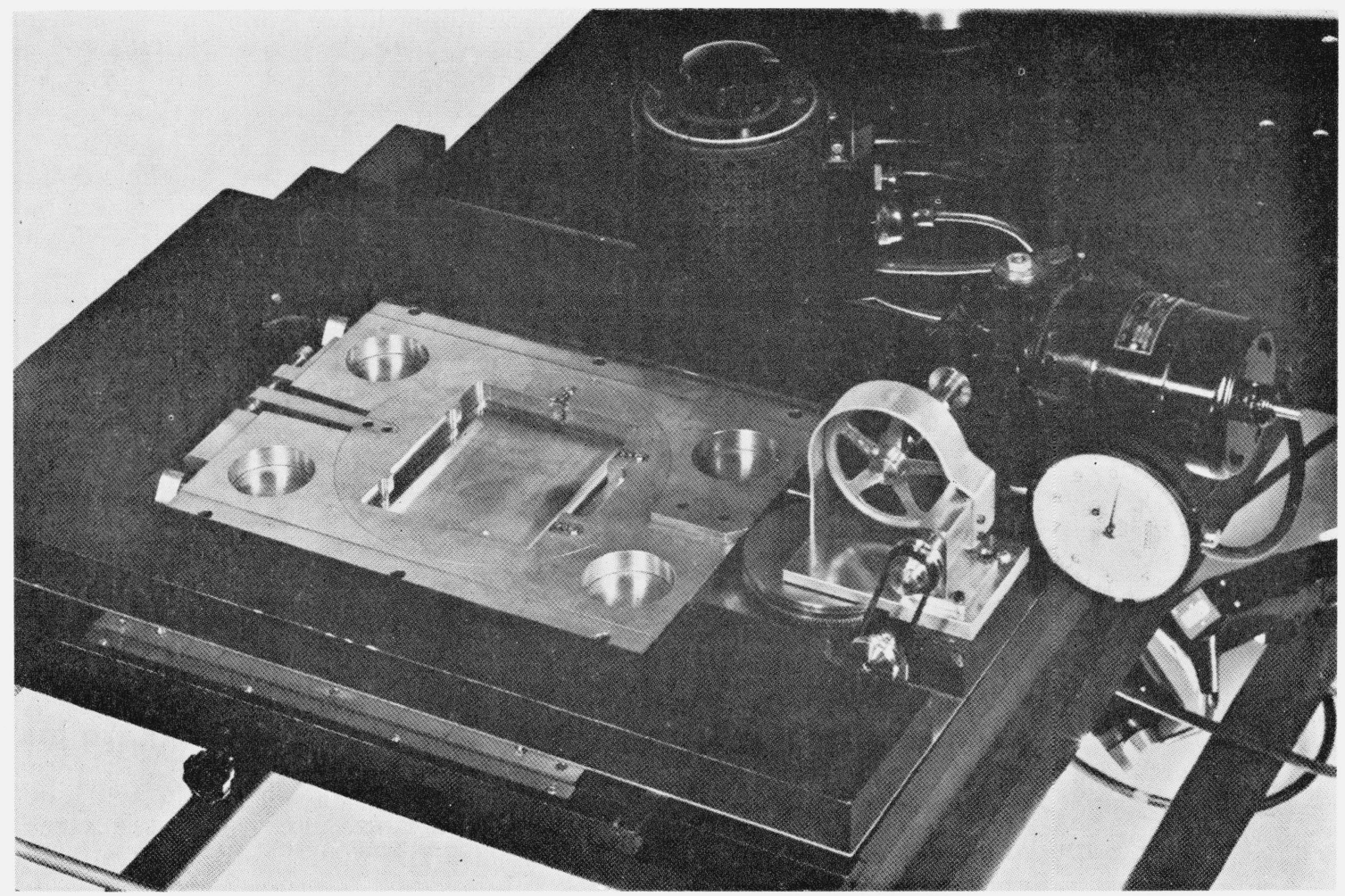

Figure 9. Film viewer with motor drive.

grid before the grid was masked off. Figure 11 shows a series of streak photographs of shock waves taken at various pressures. The horizontal lines were made by manually alining the mirror so that a picture of the full grid was put on the film. This provides a convenient vertical time scale on the streak photographs which are calibrated from an oscilloscope record of synchronizer pulses generated by the camera. A horizontal distance scale is made by placing narrow strips of tape on the shock tube at suitable intervals. For convenience, a 4 in. $\mathrm{x} 5$ in. Polaroid film holder is used for streak photography.

Before taking framing photographs, a calibrated streak photograph is used to estimate the average time $\left(t_{\mathrm{avg}}\right)$ for the luminous slug to pass a point on the shock tube, and the total time $\left(t_{T}\right)$ for the luminous slug to clear the region in which framing photograph investigations are to be made. These estimates are diagramed in figure 12 . The maximum rate is determined by the grid dimensions and by the total luminous time $\left(t_{T}\right)$. With a grid having a slit spacing $D$, the maximum permissible mirror rotation frequency without double exposure is given by:

$$
\begin{aligned}
f & <\frac{D}{4 \pi r t_{T}} . \\
r & =\text { Optical arm of camera (inches). } \\
t_{T} & =\text { Total luminous time (seconds). } \\
f & =\text { Mirror rotation frequency (cycles per second). } \\
D & =\text { Grid slit spacing (inches). }
\end{aligned}
$$

Figure 13 shows a sequence of single frame photographs without double exposure. Although no double exposures occur on this photograph, resolution of the luminous front of the shock wave is rather poor because of the relatively low framing rate used. Still, the luminosity form and velocity can be observed quite well.

In general it is desirable to obtain double exposures so that velocity measurements and changes in luminosity patterns can be observed on one photograph. In addition, by allowing double exposures higher framing rates can be achieved. However, the maximum camera speed is limited by the time $\left(t_{\text {avg }}\right)$ for the luminous slug to pass a point on the shock tube in the region of interest, and by the grid spacing $D$. Maximum camera speed is given by:

$$
\begin{aligned}
& f=\frac{D}{4 \pi r t_{\text {avg }}} . \\
& f=\text { Mirror rotation speed (cycles per second). } \\
& D=\text { Grid slit spacing (inches). } \\
& r=\text { Optical arm of camera (inches). } \\
& t_{\text {avg }}=\text { Maximum time (seconds) for luminous } \\
& \text { slug to pass any point in region of } \\
& \text { interest. }
\end{aligned}
$$

Figures 14, 15, and 16 show sequences of mutiple exposure photographs. Note the complex patterns of luminosity which are clearly visible with the better resolution of detail apparent in these photo- 


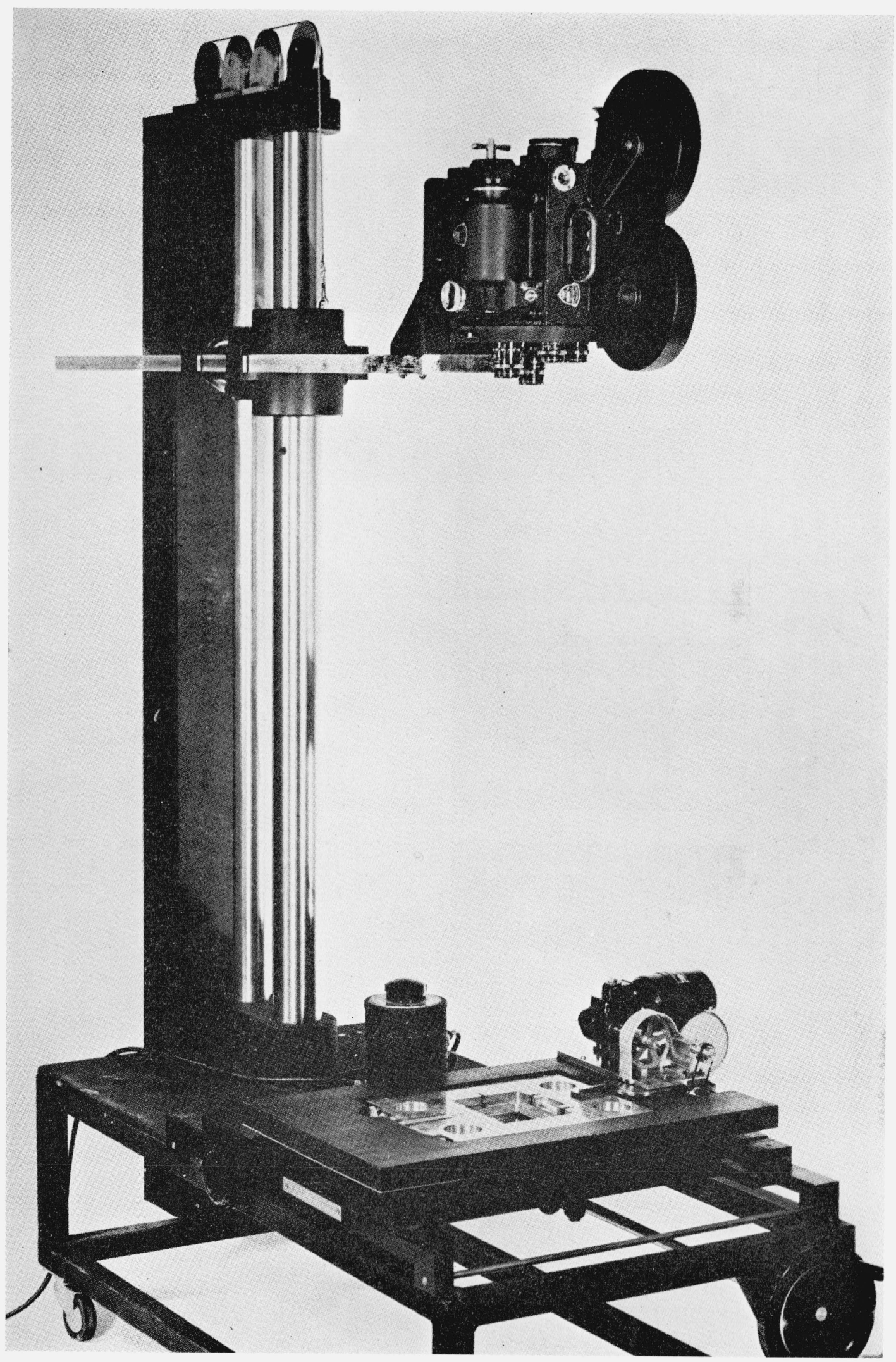

Figure 10. Arrangement for making high speed motion pictures. 


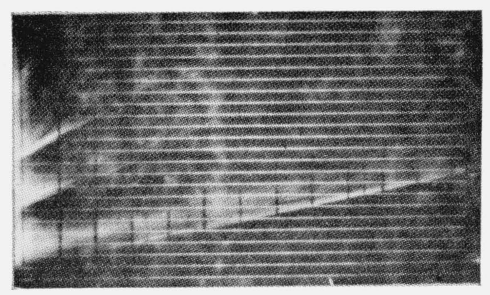

$P_{0}=50 \mu \quad \mathrm{Hg}$

TIME SCALE: $0.836 \mu$ SEC./DIV.

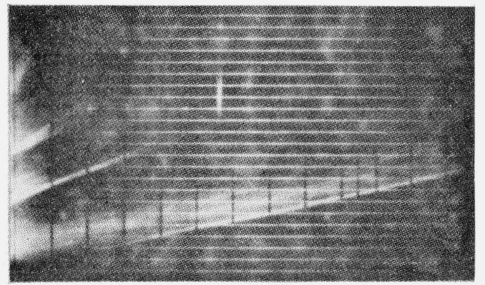

$P_{0}=100 \mu \mathrm{Hg}$

TIME SCALE: $0.836 \mu$ SEC./DIV.

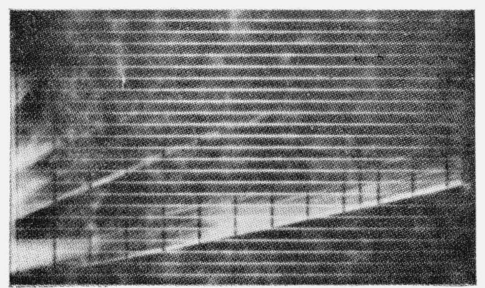

$P_{0}=200 \mu \mathrm{Hg}$

TIME SCALE: $0.840 \mu$ SEC./DIV.

$P_{0}=300 \mu \mathrm{Hg}$

TIME SCALE: $0.840 \mu$ SEC./DIV
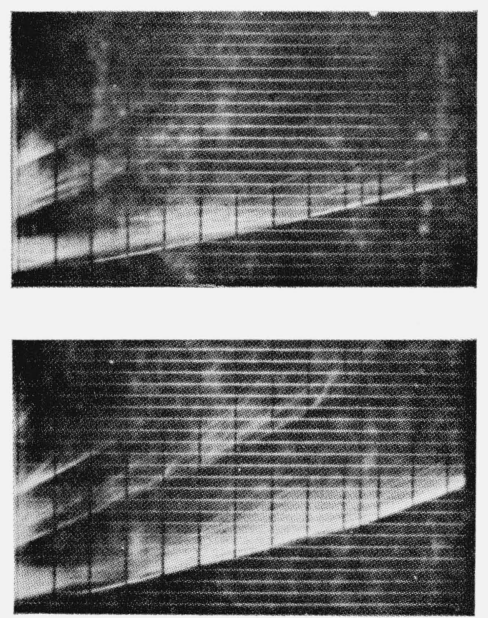

$P_{0}=500 \mu \mathrm{Hg}$

TIME SCALE: $0.844 \mu$ SEC./DIV.

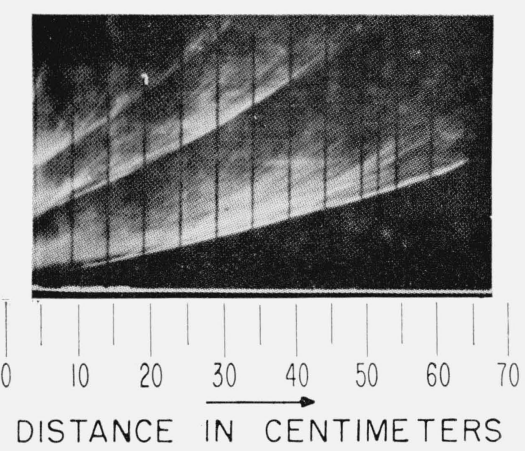

$P_{0}=1000 \mu \mathrm{Hg}$

TIME SCALE: $0.848 \mu$ SEC./DIV.

FIGURE 11. Streak photographs of shockwaves in electrically driven helium shocktube (taken at various ambient pressures). In each case energy input is 2000 joules. The shock tube is $4.15 \mathrm{~cm}$ i.d. $\times 122 \mathrm{~cm}$. long. 


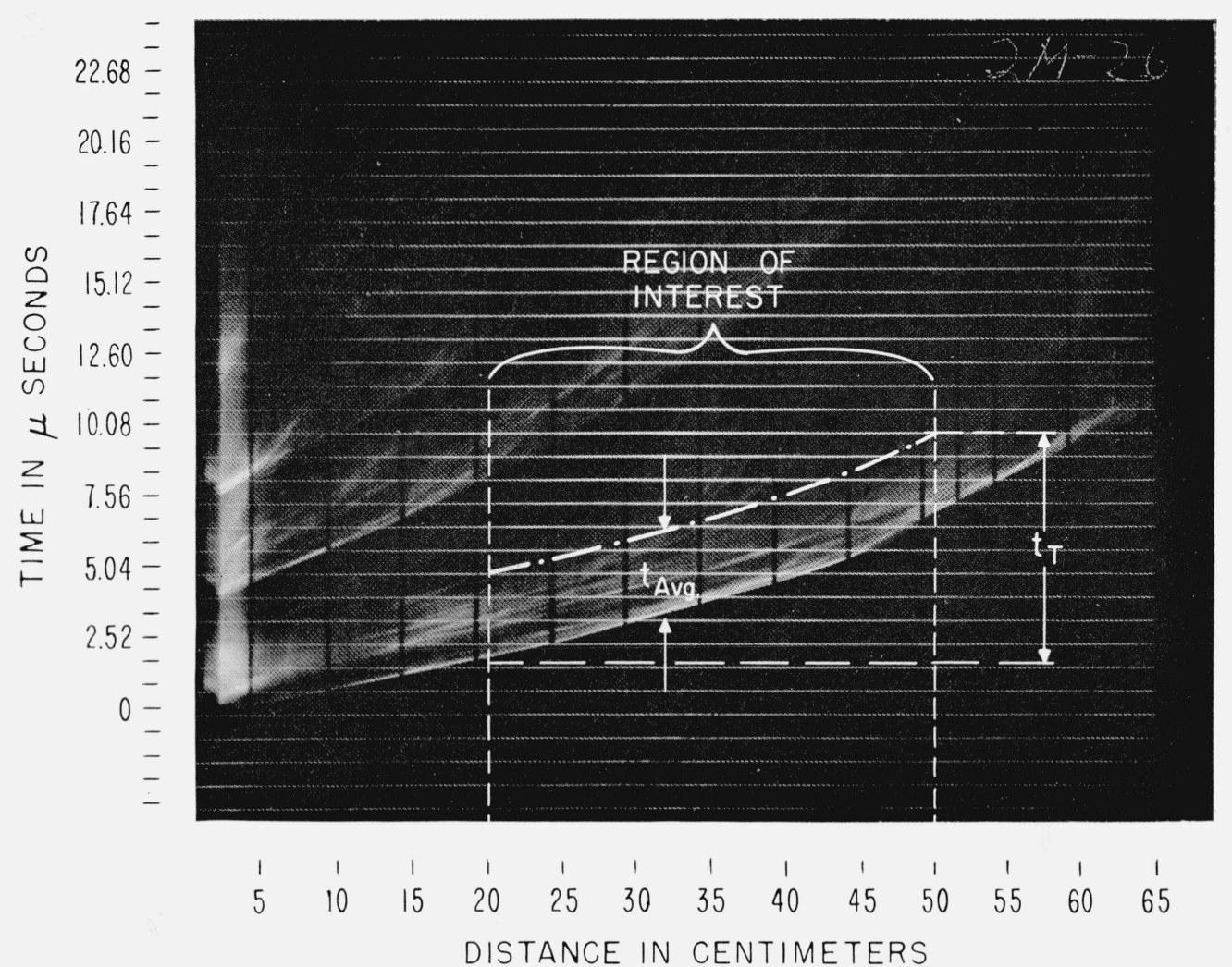

FIGURE 12. Estimates of the duration of luminosity from a streak photograph.

graphs. The luminous vertical lines observed in figures 15 and 16 are caused by the shock wave colliding with $3 \mathrm{~mm}$ o.d. glass tubes placed across the inside of the shocktube and spaced at $10-\mathrm{cm}$ intervals. To better interpret these collisions, a mirror is used to obtain two simultaneous views of the shocktube at right angles to the axis of the tube. Figure 16 shows the typical overlapping of images (on the left) caused by the luminous slug being too long to be displayed separately at the camera speed employed.

Figures 13 through 15 show only 6 out of a possible 31 sequences available. Moving pictures may be obtained by recording all of the possible photographs by using the motor driven film viewer with a $16 \mathrm{~mm}$ moving picture camera. A strip of moving picture film taken by the arrangement in figure 9 is shown in figure 17.

\section{Film}

In general, the best photographs of highly luminous shock waves have been obtained on Eastman Kodak Tri-X 4 in. x 5 in. glass plates. For events of lower luminosity, good photographs have been obtained on Kodak Spectroscopic 1-D 4 in. x 5 in. plates. Better results could no doubt be obtained with plates checked for flatness; however, no flat plates were immediately available for use in our work. Polaroid 4 in. $\mathrm{x} 5$ in. packets (types 52 and
57 ) used in a Polaroid 4 in. $x 5$ in. film holder have been used for all streak photography. The Polaroid film is also useful in checking camera synchronization and for rapidly estimating the correct exposure for framing photography.

\section{Summary and Conclusions}

The Sultanoff type of high-speed image dissecting camera has proved to be a very useful tool in obtaining streak and frame photographs of very highspeed shock waves. Motion pictures may be obtained of events too fast to record by any other type of motion picture camera. In addition, if some sacrifice in picture detail can be tolerated, the simplicity in design of this camera allows for a much less expensive fabrication than is possible in other types of high-speed cameras. By using a variety of grids, streak and framing photographs may be taken of a wide variety of self-luminous events, and throughout a broad range of framing rates.

Some of the disadvantages of the camera should be mentioned. The event to be photographed must be synchronized to the camera, since it is not continuous writing. In addition, the achievable camera speed is limited by the time required for luminosity to decay appreciably at any given point of interest. For example, events which are strongly luminous for long periods of time will place serious limits on the framing rates that are possible. The higher framing 

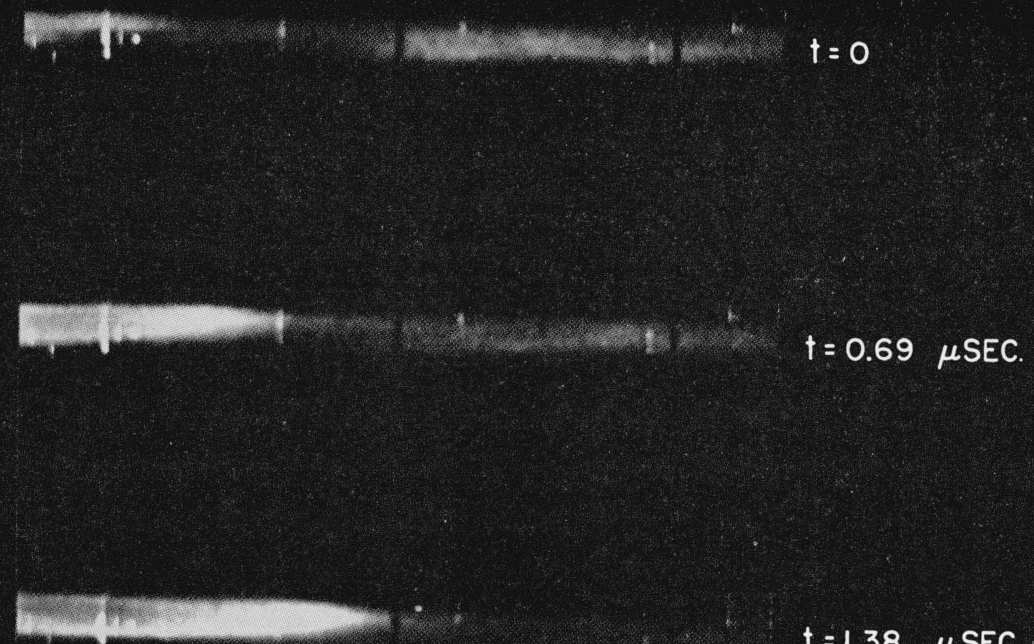

$\mathrm{t}=\mathrm{I} .38 \boldsymbol{\mu S E C}$.

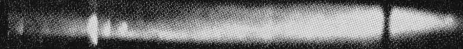

$t=2.07 \mu$ SEC

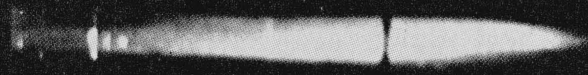

$t=2.76 \mu$ SEC.

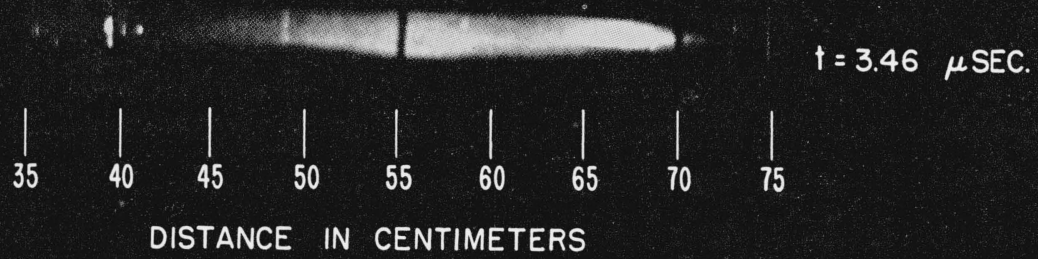

FIGURE 13. A sequence of six single exposure photographs of a shock wave in helium at 175 $\mu$ Hg, using the same shocktube as in figure 11.

The effective framing rate is $5.57 \times 10^{6} /$ second. Energy input is 2000 joules. 


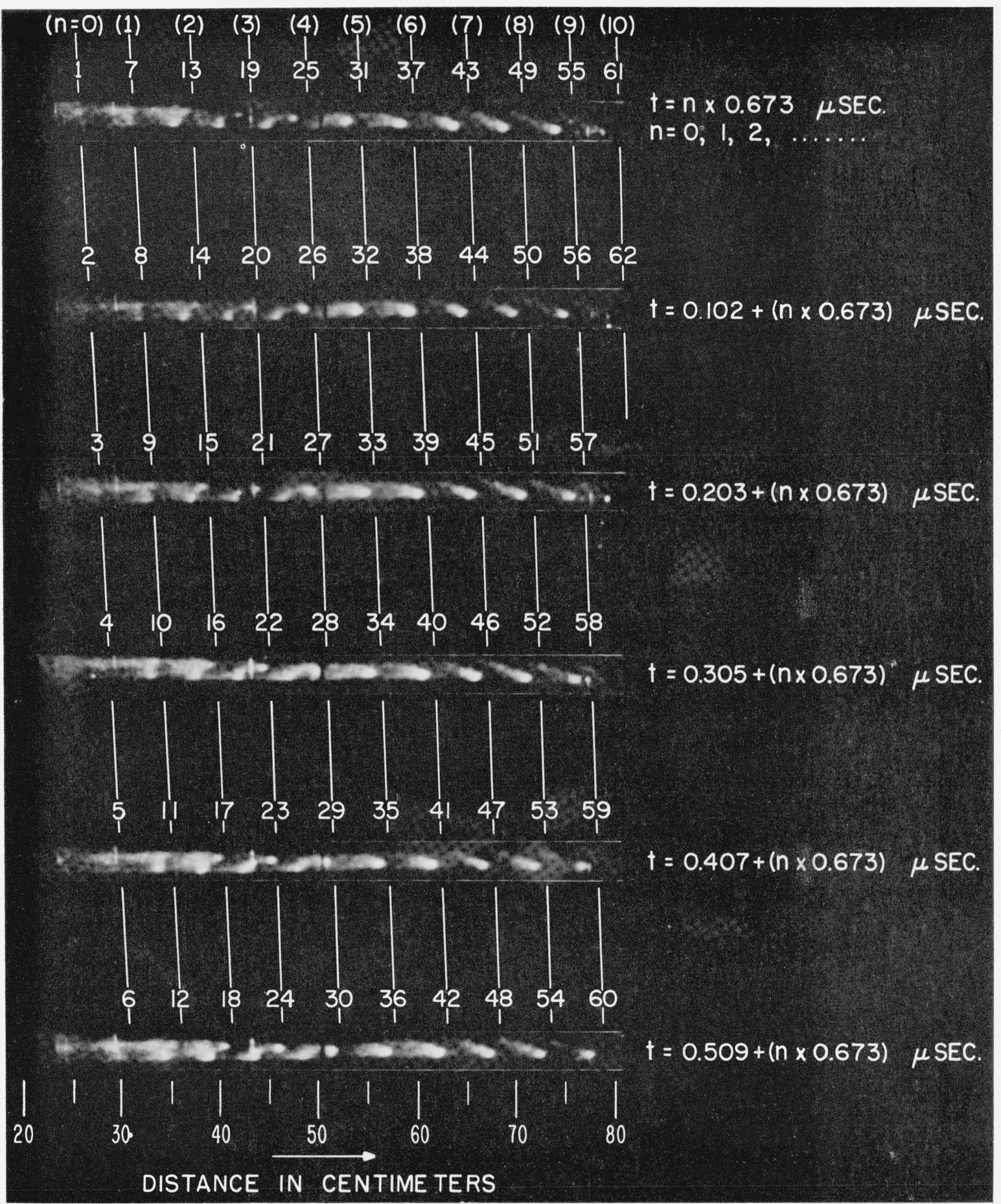

Figure 14. A sequence of six multiple exposure photographs of a shock wave in helium at $150 \mu \mathrm{Hg}$, using the same shocktube as in figure 11.

The effective framing rate is $48 \times 10^{0} /$ second. Shock waves are numbered in time sequence. A complex interaction of the shock wave with the shocktube walls may be observed in these photographs. 


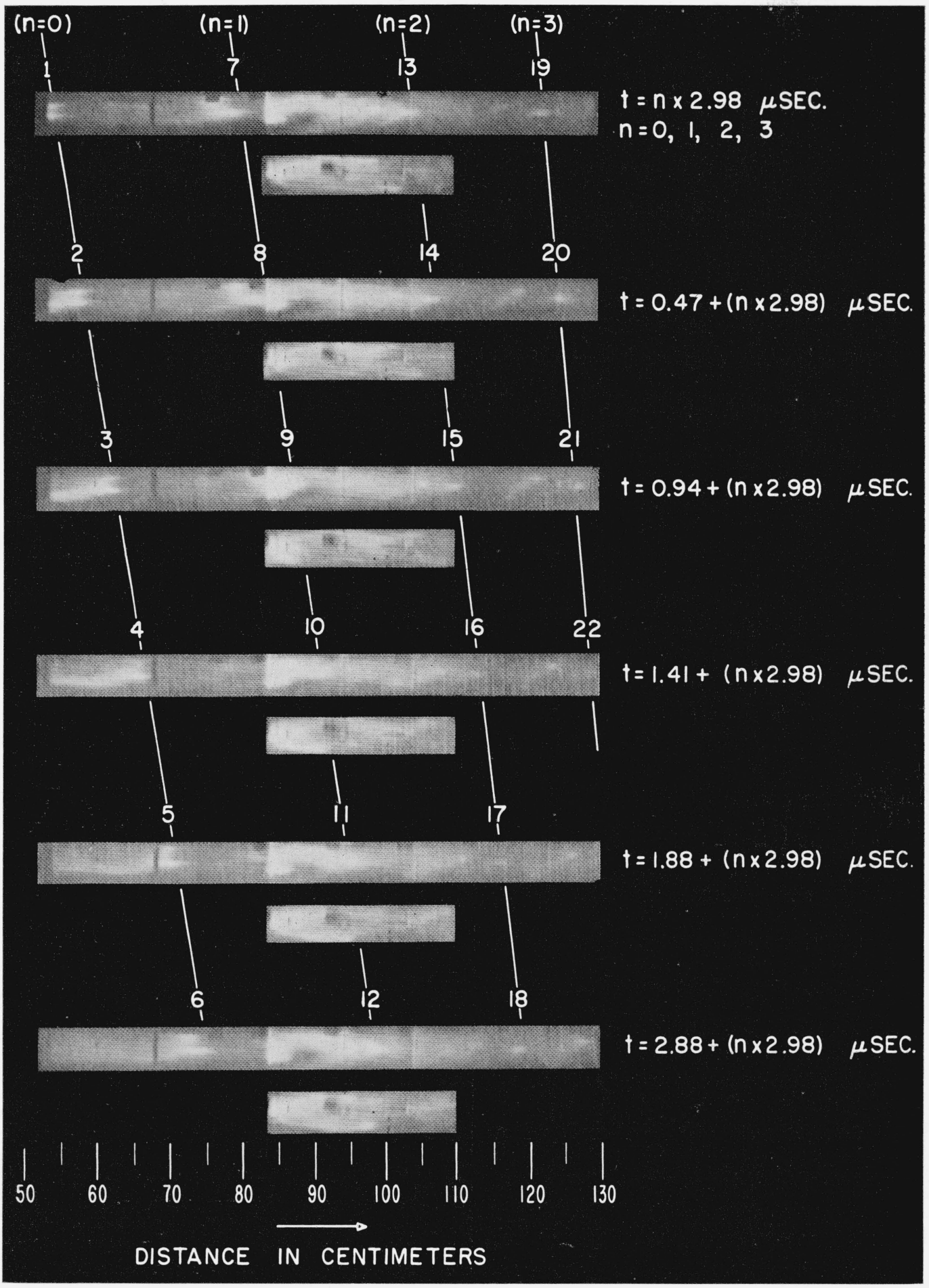

Figure 15. A sequence of six multiple exposure photographs of a shock wave in helium at $50 \mu \mathrm{Hg}$.

The effective framing rate is $10.4 \times 10^{6} / \mathrm{second}$. The shocktube has a $5.25 \mathrm{~cm}$ i.d. and a length of $152 \mathrm{~cm}$. A mirrored view (under each picture) gives a stereoseopic analysis of the collisions with obstructions inside the shocktube. In this figure and in figure 16 , note the bow wave pattern produced by the obstructions. 


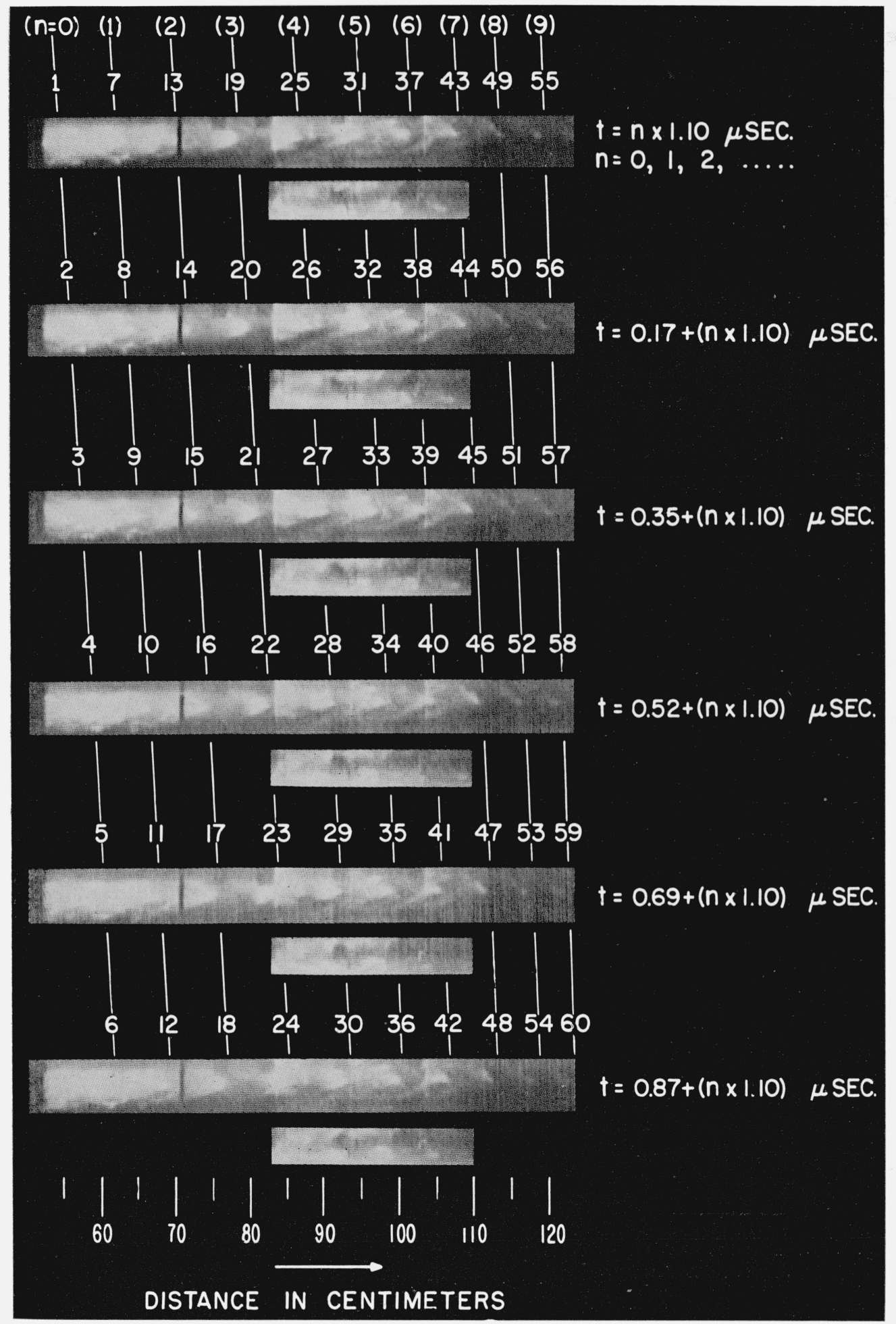

FIGURE 16. A sequence of six multiple exposure photographs of a shock wave in helium at $50 \mu \mathrm{Hg}$, using the same shocktube as in figure 15 .

The effective framing rate is $28.2 \times 10^{6} /$ second. 


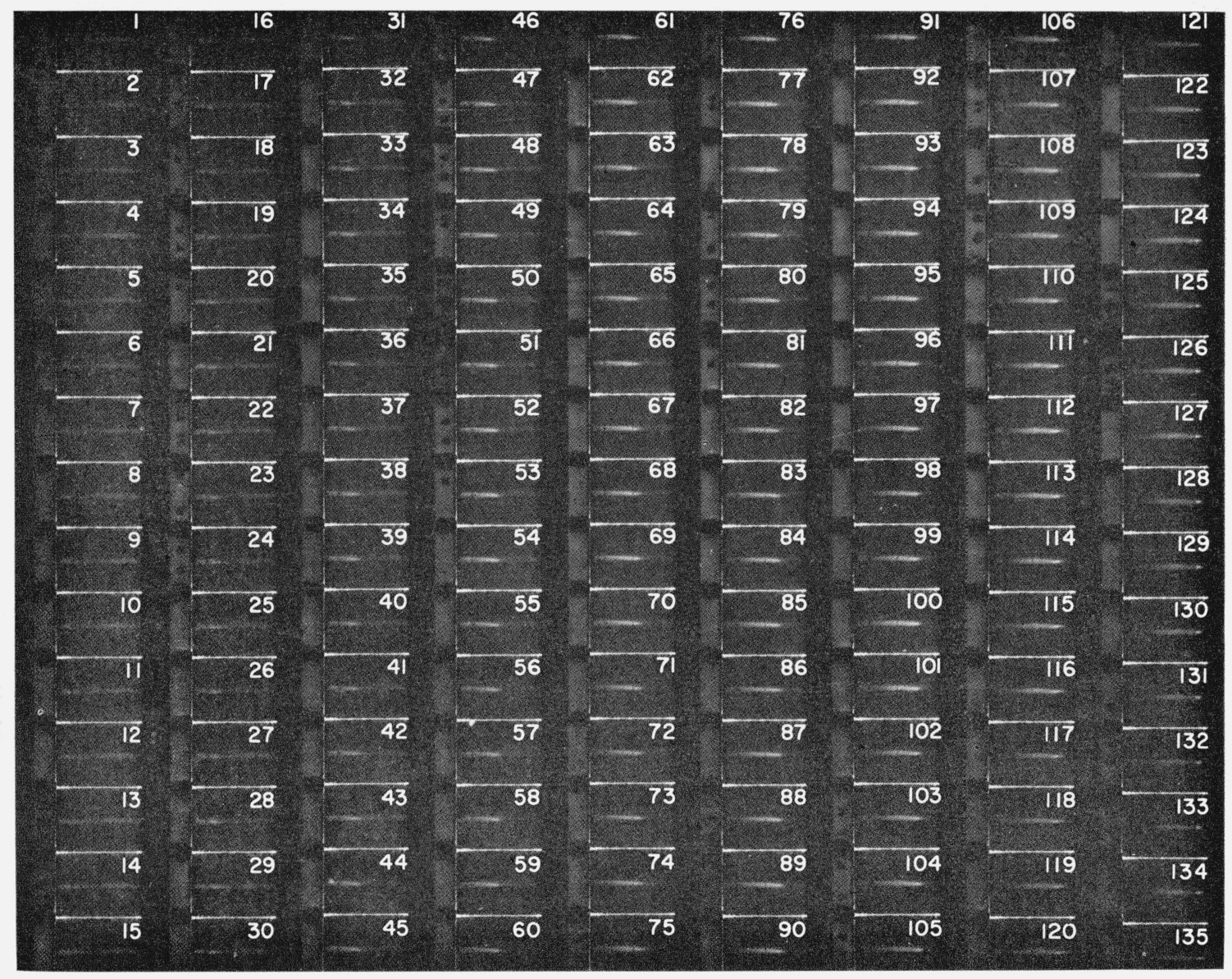

FIGURE 17. A sequence of 135 pictures taken from a $16 \mathrm{~mm}$ moving picture film of the event displayed in figure 13 .

rates in this case can be achieved only by further sacrifices in resolution by using a grid having a wide spacing between slits or by using a smaller enlargement (or greater diminution) of the event being photographed. In other words, for slowly changing luminosity patterns, a greater sacrifice in resolution is necessary to obtain the higher framing rates.

Although these disadvantages do exist for certain self luminous events, the Sultanoff camera is particularly well adapted to motion picture studies of very high velocity shock waves.

The authors express their thanks to C. M. Shepherd for his help in designing the viewer and to W. R. Saxton, R. D. Dickason, and T. L. Theotokatos for their help in obtaining the photographs presented in this report.

\section{References}

[1] Sultanoff, M., A 100,000,000 frame per second camera, Rev. Sci. Inst. 21, 7, 653-656 (July 1950).

2] Jones, G. A., High speed photography (John Wiley \& Sons, Inc., New York, N.Y., 1952).
[3] Waddell, J. H., High speed photography in the United States, Science and Applications of Photography (Proceedings of the Royal Photographic Society Centenary Conference): London, 1953, pp. 384-387. Published by the Royal Photographic Society of Great Britain, London, S.W. 7. (1955)

[4] Courtney-Pratt, J. S., Review of methods of high speed photography, Reports on Progress in Physics 20, 379-432 (1957).

\section{Appendix I. Components Used in the Ultra-High Speed Camera}

A numbered layout of the high-speed camera is given in figure 18 . The numbered parts are:

1. The basic camera frame, the rotating mirror, and the grid holders 1 (a) were manufactured by the Buck Instrument Company, Boulder, Colo. The image dissecting grids 1 (b) were manufactured by the Bausch \& Lomb Optical Company. The 8 in. focal length 4 in. $x 5$ in. Fresnel lens 1 (c) may be obtained as a standard item at almost any photographic supply house.

2. The mirror drive motor is a Precise Super 40 high-speed grinder motor. 


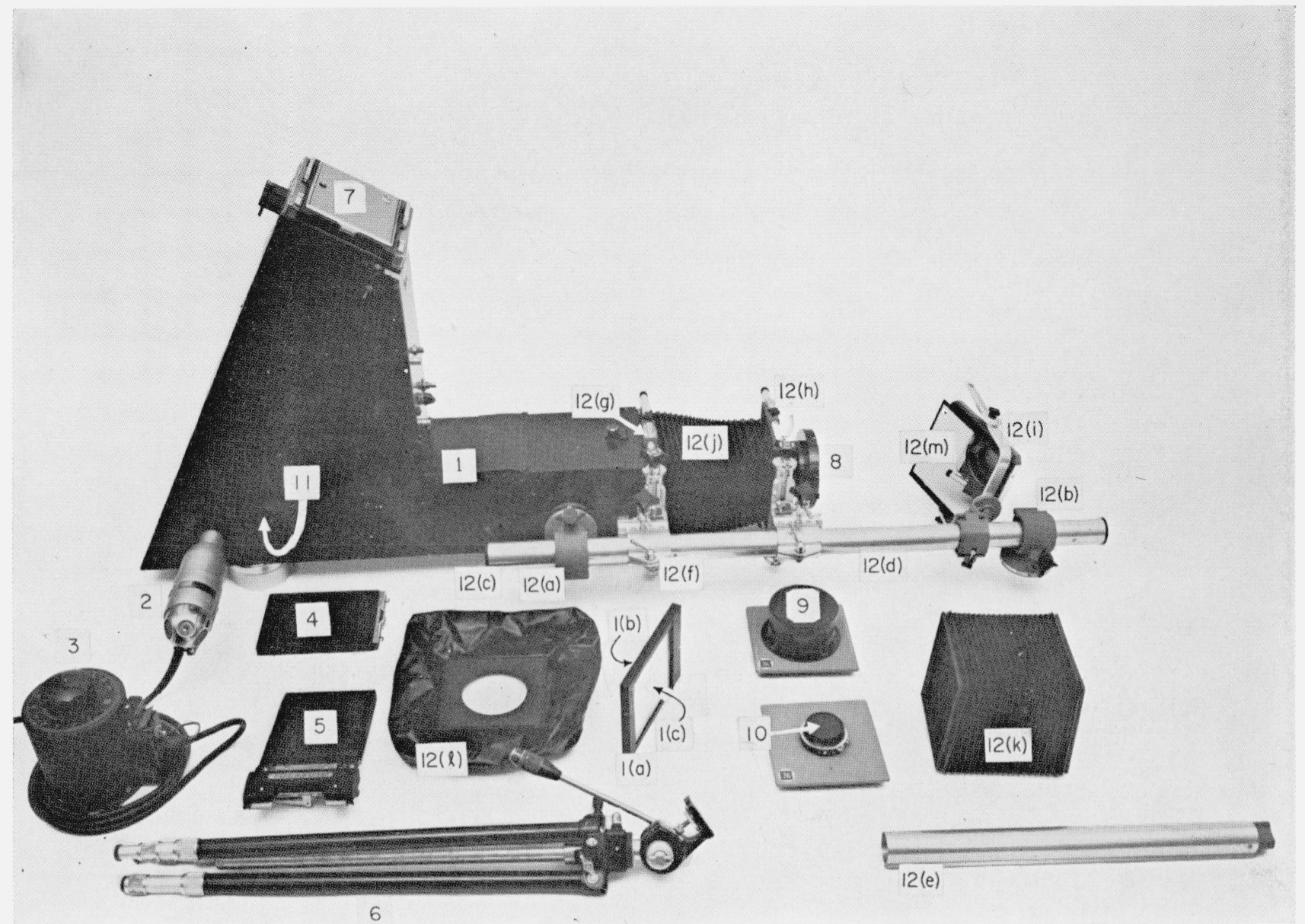

Figure 18. A layout of high speed camera parts.

3. $110 \mathrm{~V}, 60 \sim$ Variac motor speed control.

4. 4 in. $x 5$ in. Graphic photographic plate holder.

5. Polaroid 4 in. $x 5$ in. flat film holder.

6. Tripod support; the main camera is supported on a movable stand and the tripod is used only for supporting the front of the camera at the tripod mount (12b).

7. Linhof tecknika 4 in. $x 5$ in. adjustable and revolving camera back. This camera back is furnished with a bellows which has been cut off short and attached to the camera frame. The camera back is mounted on a frame which is held to the main camera frame by three adjustable screws. Correct alinement of the camera back is accomplished by adjusting the three screws (which are locked in position after alinement is correct).

8. Kodak Aero-Ektar lens, F/2.5, 7 in. focal length.

9. Ilex Paragon anastigmatic, F/4.5, 12 in. focal length.
10. Schneider-Kreuznach Symmar, F/5.6 5.6 in. focal length.

11. Re-imaging lens (lens 2 in fig. 4): Georz Artar, $\mathrm{F} / 9.5,10^{3 / 4}$ in. focal length.

12. Sinar commercial view camera, including:

(a) and (b) Two bench holders with sleeves. Bench holder (b) is used with the tripod.

(c) 6 in. extension bench unit.

(d) 18 in. extension bench unit.

(e) 12 in. extension bench unit.

(f) Joint block.

(g) 4 in. $\mathrm{x} 5$ in. rear carrier.

(h) Front principal frame, with 3 lens boards.

(i) Auxiliary frame.

(j) 4 in. $x 5$ in. tapered bellows.

(k) Square bellows extension.

(l) 4 in. $x 5$ in. wide angle bellows.

(m) Front surface mirror.

(Paper 66C4-105) 